\title{
Estéticas y estigmas de/en la geografía imaginada de la telenovela brasileña*
}

\author{
Lucas Martins Néia | lucas_martins_neia@hotmail.com \\ Universidad de São Paulo
}

\author{
Palabras clave \\ "telenovela brasileña", "geografías imaginadas", \\ "brasilidad", "identidad nacional”, "imagina- \\ ción moderna" \\ Sumario \\ 1. Introducción: ¿cómo la ficción televisiva \\ moldea un país? \\ 2. Diálogos entre la Comunicación, la Geo- \\ grafía y los Estudios Culturales: una estrategia \\ teórico-metodológica \\ 3. Marco muestral y categorías de análisis \\ 4. Entre los "espacios narrados" y los "espacios \\ vividos” de la nación brasileña \\ 5. Consideraciones finales \\ 6. Bibliografía
}

\section{Resumen}

El artículo surge de una investigación que se propuso trazar una historia cultural de las telenovelas en Brasil, entendiéndolas como la experiencia comunicacional, estética y social que mejor ha caracterizado una narrativa de la nación brasileña (Vassallo de Lopes, 2009) en los últimos 60 años. La espacialidad fue tomada como la principal variable en la estrategia teórico-metodológica del trabajo; a partir de autores como Said (1978) y Anderson (1983), buscamos reflexionar sobre la capacidad de la ficción televisiva en la articulación y legitimación de geografías imaginadas. Constatamos que las telenovelas brasileñas se apropiaron gradualmente de la densidad geo-cultural y de la imaginación moderna del país: el mestizaje (Martín-Barbero, 1998) entre dispositivos narrativos tradicionales, tecnicidades emergentes y nociones socio-identitarias hizo que esas producciones actuasen en la reorganización de sentidos referentes a la cuestión nacional. Sin embargo, la retroalimentación entre el melodrama y la brasilidad en tales narrativas no dejó de perpetuar estigmas y patrones de exclusión observados en otras ramas de la cultura.

\section{Cómo citar este texto:}

Lucas Martins Néia (2022): Estéticas y estigmas de/en la geografía imaginada de la telenovela brasileña, en Miguel Hernández Communication Journal, Vol. 13 (1), pp. 81 a 100. Universidad Miguel Hernández, UMH (Elche-Alicante). DOI: 10.21134/mhjournal. v13i.1465

${ }^{*}$ El presente trabajo contó con el apoyo y la subvención de la Coordinación de Perfeccionamiento de Personal de Nivel Superior (CAPES), Brasil; Código de Financiación 001. 


\title{
Aesthetics and Stigmas of and in the Brazilian Telenovela's Imagined Geography*
}

\author{
Lucas Martins Néia | lucas_martins_neia@hotmail.com \\ Universidad de São Paulo
}

\author{
Keywords \\ "Brazilian telenovela", "imagined geographies", \\ "Brazilianness", "national identity", "modern \\ imagination" \\ Summary \\ 1. Introduction: How Does TV Fiction Build a \\ Nation? \\ 2. Dialogues Among Communications, Geogra- \\ phy, and Cultural Studies: A Theoretical-Method- \\ ological Strategy \\ 3. Sampling Frame and Categories of Analysis \\ 4. Between "Narrated Spaces" and "Lived Spaces" \\ of the Brazilian Nation \\ 5. Final Remarks \\ 6. Bibliography
}

\begin{abstract}
This paper arises from a research project that proposed to draw a cultural history of telenovelas in Brazil, understanding them as the communicational, aesthetics, and social experience that has best characterised a narrative of the Brazilian nation (Vassallo de Lopes, 2009) in the last 60 years. Spatiality was taken as the main variable in the theoretical-methodological strategy of this analysis; based on Said's (1978) and Anderson's (1983) conceptualisations, it was possible to reflect on the ability of TV fiction to articulate and legitimize imagined geographies. On the whole, Brazilian telenovelas have gradual-
\end{abstract} ly appropriated the geocultural density and the modern imagination of the country: the mestizaje (Martín-Barbero, 1998) of traditional narrative devices, emerging technicities, and socio-identity notions made these productions act in the reorganisation of meanings referring to the national issue. The relationship between melodrama and Brazilianness at the core of such narratives, nonetheless, has never stopped inflicting a symbolic violence inasmuch as it perpetuates stigmas and patterns of exclusion observed in other spheres of culture.

Lucas Martins Néia (2022): Estéticas y estigmas de/en la geografía imaginada de la telenovela brasileña, en Miguel Hernández Communication Journal, Vol. 13 (1), pp. 81 a 100. Universidad Miguel Hernández, UMH (Elche-Alicante). DOI: $10.21134 /$ mhjournal. v13i.1465

*This study was financed in part by CAPES Foundation, Brazil; Funding Code 001. 


\section{Introducción: ¿cómo la ficción televisiva moldea un país?}

Productos televisivos imperantes en Latinoamérica (Martín-Barbero, 1998), las telenovelas adquirieron características singulares en Brasil al apropiarse de temas emergentes en la esfera pública del país utilizando las reglas del melodrama. Es por ello que Vassallo de Lopes (2009) afirma que tales ficciones se han convertido en la experiencia comunicativa, cultural, estética y social que mejor ha caracterizado la narrativa de la nación brasileña.

En sus reflexiones, Vassallo de Lopes parte fundamentalmente del concepto de comunidad imaginada. A través del mismo, Anderson (1983) asocia el surgimiento de la prensa escrita de masas y de las lenguas nacionales con la consolidación del sentido de pertenencia de los sujetos a una comunidad que podemos llamar de "patria”. Según Saliba (2002), la asociación de los imaginarios de los Estados Nación con los sistemas culturales que los precedieron, con los cuales (y contra los cuales) nacieron los Estados nación, otorga al concepto de nación una dimensión trascendente. Esta característica se explora más a fondo en las acepciones de Bhabha (1990), para quien las naciones y la noción misma de cultura pueden ser aprehendidas como construcciones narrativas.

Tales cuestiones resultan útiles para comprender la dimensión de las telenovelas en Brasil. El hecho de que estos programas sean vistos diariamente, en una misma franja horaria, durante las últimas décadas, se fue transformando paulatinamente en un ritual compartido por varias personas en todo el territorio nacional, que pasaron utilizar los patrones forjados por ellos como referencias para definir tipos ideales de familia brasileña, mujer brasileña, hombre brasileño y también de corrupción brasileña, violencia brasileña, etc. (Vassallo de Lopes, 2009). De esta manera, se puede emplear la idea de comunidad imaginada con el objetivo de hacer un diagnóstico de las nociones de brasilidad construidas por la ficción televisiva.

Recurrimos a la variable espacialidad y sus interfaces en los "mundos narrados" de la telenovela y en el "mundo vivido" (o "mundos vividos") de la nación para observar cómo los sentidos y constructos de identidad nacional se constituyeron y se reconfiguraron en la diacronía de las ficciones televisivas en Brasil. Para ello, nos guiamos por la hipótesis de que, en los últimos 60 años, el melodrama ha operado como articulador de significados y dilemas de la brasilidad -tanto patentes como latentes- en la arena de la producción, la circulación y la recepción de sentidos articulada por las telenovelas producidas en el país.

Con respecto al melodrama, nos basamos en estudios como los de Gledhill (1987, 2000), quien lo clasifica como un modo de percepción y articulación estética adaptable transversalmente a una amplia gama de géneros y culturas nacionales. Gledhill toma de la sociolingüística la noción de modalidad -la capacidad de dar estructura a ciertos fenómenos culturales para comprender el conjunto de reglas que los involucra- para investigar el melodrama como un sistema imaginativo provisto de un campo de fuerzas semántico y de una percepción propia de experiencias estéticas y emocionales.

Martín-Barbero (1992b, 1998), de alguna manera, se acerca a tal concepción cuando enfatiza que en América Latina el imaginario melodramático se configura como una matriz cultural 
de los relatos tanto cinematográficos como televisivos. El comunicólogo hispano-colombiano reconoce al melodrama como un género en un campo más cercano a la pragmática de la Comunicación que a la semiótica textual. Según Gomes (2011), en este proceso, el género no sería una propiedad de los textos, sino algo que los atraviesa, una estrategia que vincula la producción y el consumo de los contenidos mediáticos.

Pensar el melodrama como un fenómeno transcultural y transgénero nos ofrece un puente conceptual más preciso entre estas perspectivas (Néia, 2018). Es precisamente a través de este modo/género dotado de propiedades sincréticas y niveladoras que las telenovelas brasileñas moldearon (y siguen moldeando) al país y a otras localidades del mundo en un doble sentido: tanto moldurando como modelando nociones de territorio y, en consecuencia, de brasilidad (a veces en contraposición a otras nacionalidades).

Para explorar cómo a lo largo de su historia la telenovela brasileña ha forjado ideales de nacionalidad que incorporaron la ética y la estética melodramáticas, evocamos un cuerpo teórico capaz de subsidiar epistemológica y metodológicamente nuestras reflexiones sobre las relaciones entre lugar, cultura, identidad y los medios de comunicación.

\section{Diálogos entre la Comunicación, la Geografía y los Estudios Culturales: una estrategia teórico-metodológica}

Al lanzarnos a una reflexión sobre las experiencias culturales, estéticas y sociales proporcionadas por las ficciones televisivas en Brasil en las últimas seis décadas, buscamos dotarnos de una mirada y de un pensamiento interpretativo extra disciplinario (Morin, 2007). Actuamos, por lo tanto, en línea con los conceptos de Vassallo de Lopes (2004), Sodré (2014) y Fuentes-Navarro (2021) en cuanto a perspectivas epistemológicas, teóricas y metodológicas del campo de la Comunicación, convocando parámetros relevantes para la Geografía y los Estudios Culturales en la realización de este trabajo.

Partimos de la teoría barberiana de la comunicación (Vassallo de Lopes, 2018) para comprender las continuidades y rupturas, las disputas sobre los significados de la identidad nacional y sus movimientos de retroalimentación con el ethos melodramático en la diacronía de la telenovela brasileña. Las reflexiones de Jesús Martín-Barbero nos resultaron útiles al ofrecer claves teórico-analíticas propias a la identificación de las mutaciones culturales involucradas en la trayectoria de la teleficción en Brasil a lo largo de los años, además de permitir la visualización de estructuras, operaciones y maniobras técnicas, sociales y políticas emprendidas por la industria televisiva en la construcción de representaciones.

Para investigar las dimensiones espaciales de los constructos de la brasilidad reconfigurados y resemantizados en la historia de la telenovela brasileña, recurrimos al mapa metodológico de las mediaciones elaborado por Martín-Barbero en 2017. Con el título de mapa de las mutaciones culturales y comunicativas, este esquema rizomático toma las mediaciones como detonantes y síntomas de transformaciones que involucran tiempos y espacios, demostrando la maduración de algunas reflexiones ya propuestas por el comunicólogo en su mapa de 2010. 
Figura 1. Mapa barberiano de las mutaciones culturales y comunicativas (2017)

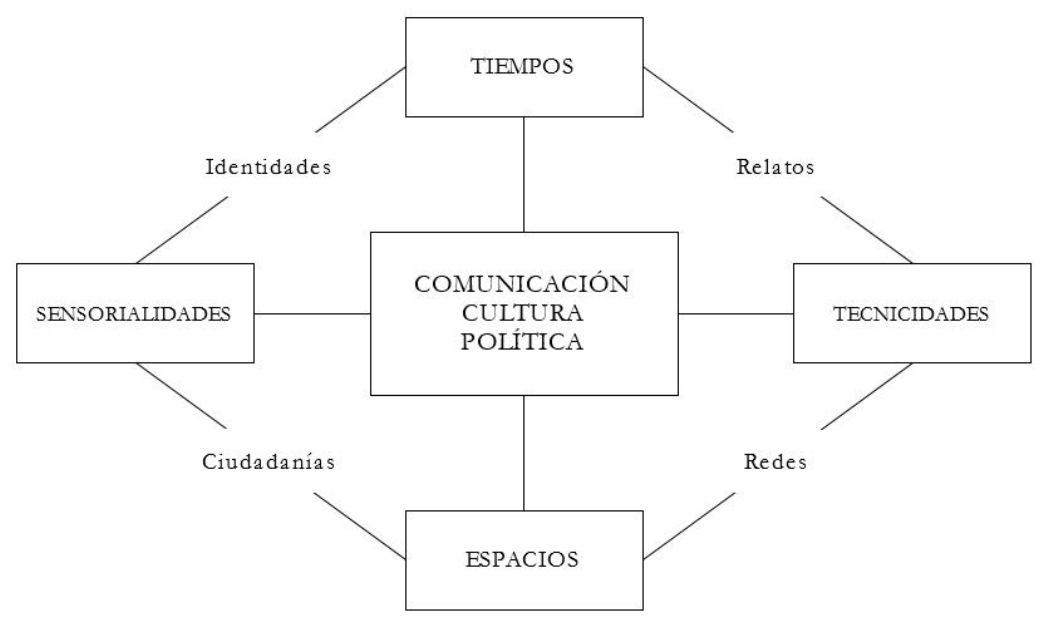

Fuente: Vassallo de Lopes (2018: 58)

A través de estos diagramas, Martín-Barbero reflexiona sobre la crisis de la experiencia moderna del tiempo, la cual es percibida por medio de las profundas transfiguraciones observadas en la estructura temporal del presente, la debilidad establecida en nuestra relación histórica con el pasado y la multiplicidad de tiempos vividos en la simultaneidad del presente. El espacio también se desacopla en múltiples instancias. Por ejemplo, se verifica la existencia del espacio habitado -territorio hecho de proximidad y pertenencia-, del espacio comunicacional tejido por los medios digitales y del espacio imaginado de la nación junto con las nociones de identidad que ésta retroalimenta. (Vassallo de Lopes, 2018)

Considerando el objeto y los objetivos de esta investigación, ubicamos a la telenovela brasileña en la sub-mediación de los relatos, tensada por las mediaciones básicas de tecnicidades y temporalidades - es decir, sujeta a las competencias del lenguaje y a las posibilidades tecno-estéticas vigentes en un determinado momento-. Por lo tanto, es posible escudriñar históricamente cómo las conexiones en redes, desencadenadas por las ficciones televisivas en Brasil, comenzaron a inscribirse en los procesos de narración e interpretación de la nación. La mediación de la espacialidad, de esta manera, está anclada precisamente en la idea de comunidad imaginada (Anderson, 1983).

Partimos de una concepción de red que alude al conjunto de relaciones sociales que se establecen en espacios de convivencia y conectividad, sean ellos concretos (la vecindad) o abstractos (la nación) ${ }^{1}$ (Brignol, Cogo \& Lago Martínez, 2019). En este caso, estas redes se refieren a los territorios de producción, circulación y recepción de sentidos establecidos

${ }^{1}$ En la contemporaneidad, estas interacciones se desarrollan en ambientes digitales, constituyendo dinámicas y procesos centrales de las mutaciones comunicativas y culturales de nuestro tiempo. (Brignol, Cogo y Lago Martínez, 2019) 
por la telenovela brasileña. Se trata de un tejido que engloba a millones de espectadores, co-constructores de estas "obras abiertas", escritas en simultáneo con su emisión -y en el que historias, identidades, representaciones y recuerdos vienen siendo reelaborados y resemantizados desde la década de 1960 (Motter, 2001; Vassallo de Lopes, 2009)-.

Para pensar en los sentidos de la identidad nacional idealizados y reconfigurados en el proceso histórico de la ficción televisiva en Brasil, debemos mirar hacia las dos sub-mediaciones de la izquierda: ciudadanías e identidades. Estos constructos se forjan en el "reparto de un sensible" (Rancière, 2005) melodramático, o sea, de un sensorium retroalimentado por el melodrama en cada época. Sifuentes y Zanini (2019) enfatizan que, ligada a las temporalidades, la mediación de las identidades nos reporta a lazos de pertenencia y estructuras de significado (Geertz, 1989) -o, en otras palabras, a estrategias posicionales y políticas de autorreconocimiento por parte de individuos y grupos sociales (Rincón, 2019)-.

A su vez, las ciudadanías dialogan directamente con las espacialidades y cargan "la densidad cultural del territorio" (Rincón, 2019: 271), asumiendo la nacionalidad (Bonin \& Morigi, 2019). Al igual que ocurre con la nación, también en las ficciones televisivas hay ciudadanos imaginados (García Canclini, 1996). Es en este sentido que las sensorialidades proceden a la construcción de una pedagogía de lo que significa ser brasileño (Kornis, 2011) en el seno de las telenovelas producidas en el país.

Vista desde la perspectiva de las sensorialidades, la telenovela brasileña y su matriz. cultural, el melodrama, se traducen en lazos de afecto, tocando la vida cotidiana y, como ella, viviendo el tiempo de la repetición y la anacronía (Martín-Barbero, 1992a). En el otro extremo, la mediación de las tecnicidades -no sólo vinculada a aparatos, sino también a operadores perceptivos y habilidades discursivas (Martín-Barbero, 1998)- indica que los relatos televisivos se retroalimentan con la capacidad tecnológica de cada momento histórico, guiados también por la habilidad de las empresas productoras de aprovechar estos recursos para convocar nuevas percepciones y discursividades (Gomes et al., 2018).

Por fin, la mediación del espacio abarca las ciudades/regiones/naciones imaginadas por la ficción televisiva. Los territorios de/en las telenovelas producidas en Brasil emergen así como un conjunto de formas representativas de factores sociales del pasado y del presente (Santos, 1990), elaboradas a través de valores éticos y afectivos interrelacionados con prácticas, representaciones, relaciones espaciales, sentidos de pertenencia y aprehensiones cognitivas (Bonnemaison \& Cambrèzy, 1996; Escobar, 2000; Haesbaert, 2011) de los brasileños. Incluso a nivel del imaginario, estos territorios fueron objeto de disputas políticas, intelectuales y morales (Said, 1978; Anderson, 1983). Tales luchas se dieron en medio de una interacción desigual entre diferentes actores - un reflejo de estigmas y contradicciones en la formación socio-histórica del país que reverberaron (y aún reverberan) en la sociedad-.

\section{Marco muestral y categorías de análisis}

Las problematizaciones esbozadas en el apartado anterior tomaron forma en el nivel metódico-técnico del trabajo, en el que se definen las operaciones de recolección y procesa- 


\section{MHJournal Vol. 13 (1) | Año 2022 - Artículo n 4 (197) - Páginas 81 a 100 - mhjournal.org}

miento de datos empíricos. Se intentó realizar una búsqueda exhaustiva en las telenovelas brasileñas diarias emitidas en cadena nacional ${ }^{2}$ entre los años 1963 (cuando TV Excelsior transmitió 2-5499 Ocupado $^{3}$ ) y 2020 para identificar las espacialidades desarrolladas en la trama de cada una de estas producciones.

Tabla 1. Ambientación espacial de las telenovelas brasileñas por década ${ }^{4}$

\begin{tabular}{|l|l|l|l|l|l|l|l|l|}
\hline ambient. & $\begin{array}{l}\text { ciudad } \\
\text { de São } \\
\text { Paulo }\end{array}$ & $\begin{array}{l}\text { ciudad } \\
\text { de Río } \\
\text { de } \\
\text { Janeiro }\end{array}$ & $\begin{array}{l}\text { otras } \\
\text { capitales } \\
\text { de Brasil }\end{array}$ & $\begin{array}{l}\text { interior } \\
\text { de } \\
\text { Brasil }\end{array}$ & extranjero & $\begin{array}{l}\text { otros } \\
\text { tipos }\end{array}$ & $\begin{array}{l}\text { no } \\
\text { identificada }\end{array}$ & TOTAL \\
\hline 1963 a 1970 & 38 & 10 & 5 & 24 & 36 & 0 & 75 & 188 \\
\hline 1971 a 1980 & 45 & 46 & 1 & 39 & 4 & 1 & 4 & 140 \\
\hline 1981 a 1990 & 34 & 39 & 1 & 21 & 2 & 0 & 0 & 97 \\
\hline 1991 a 2000 & 22 & 23 & 4 & 28 & 1 & 0 & 0 & 78 \\
\hline 2001 a 2010 & 26 & 30 & 1 & 29 & 3 & 0 & 0 & 89 \\
\hline 2011 a 2020 & 20 & 36 & 3 & 18 & 7 & 1 & 0 & 85 \\
\hline TOTAL & $\mathbf{1 8 5}$ & 184 & $\mathbf{1 5}$ & $\mathbf{1 5 9}$ & $\mathbf{5 3}$ & $\mathbf{2}$ & $\mathbf{7 9}$ & $\mathbf{6 7 7}$ \\
\hline
\end{tabular}

Fuente: elaborada por el autor (2022)

Contabilizamos un total de 677 títulos exhibidos en el período recortado por la investigación. Desafortunadamente, no fue posible delimitar la ambientación espacial de 79 títulos (11,7\% de la muestra total), todos ellos producidos en los primeros 11 años de nuestra recogida (1963 a 1973). La implementación de la videocinta a principios de la década de 1960 no se convirtió inmediatamente en una garantía de preservación de los archivos por parte de las emisoras brasileñas. Por razones económicas, muchas cintas terminaron siendo

${ }^{2}$ En el caso de los títulos producidos en la década de 1960, cuando aún se estaba desarrollando la noción de red, consideramos las producciones emitidas en al menos dos mercados, o por alguna emisora que formara parte de un conglomerado de televisión.

${ }^{3}$ Basada en la radionovela argentina 0597 da ocupado (1955), 2-5499 Ocupado, la primera trama emitida a diario en Brasil, es tomada como punto de partida de nuestro análisis porque consideramos la periodicidad diaria de las ficciones un rasgo sine qua non del formato telenovela -es, al fin y al cabo, uno de los mecanismos que permite que estas narrativas "se mezclen con la vida" y participen en las ritualidades y socialidades cotidianas de los telespectadores (Martín-Barbero, 1992b, 1998)-.

${ }^{4}$ En la recopilación y tratamiento de estos datos, se recurrió a una amplia gama de fuentes, desde publicaciones académicas y enciclopédicas relacionadas con la telenovela brasileña hasta sitios web utilizados por cadenas y críticos televisivos para preservar la memoria del vehículo. También se consultaron colecciones en línea de periódicos y revistas, además de bases de datos como la Hemeroteca Digital Brasileña - portal vinculado a la Biblioteca Nacional de Brasil en el que es posible consultar copias de semanarios que cubrieron el backstage de la radio y la televisión en el país entre los 1960 y 1970 - y blogs de fans que se dedican a digitalizar ediciones de este tipo de publicaciones. 
reutilizadas, mientras que otras se perdieron en accidentes como inundaciones o incendios en las instalaciones de los canales de televisión.

Además, en esta primera década de la telenovela diaria, las tramas -en su mayoría subyugadas al melodrama clásico- eran algo genéricas, pudiendo desarrollarse en cualquier lugar o temporalidad. Sin embargo, a medida que la telenovela brasileña se nacionaliza, adquiere especificidades que la caracterizan en relación con otros modelos teledramatúrgicos alrededor del mundo, la ubicación espacial de la acción comienza a configurarse, de hecho, como un elemento intrínseco a los relatos. Muchas de las sinopsis de telenovelas de la década de 1970 disponibles en las fuentes consultadas comenzaron a situar la trama espacialmente.

Algunas telenovelas brasileñas suelen presentar una especie de prólogo o primera fase que no es muy larga y que, muchas veces, no se sitúa en el mismo espacio que el resto de la narrativa. Otras, también tienen plots ${ }^{5}$ que se desarrollan al mismo tiempo en diferentes ubicaciones. Con el objetivo de estandarizar nuestra categorización, optamos por considerar como predominante la localidad en la que se concentraba la mayor cantidad de personajes o núcleos, o en que la mayor parte de la acción era desarrollada.

Cruzando los hallazgos empíricos con temas relevantes para la dinámica socio-histórica y geo-cultural en Brasil en particular -y en América Latina en general-, dividimos las narrativas que colocaron al país como escenario principal ( 543 telenovelas, representando el $80,2 \%$ de todos los títulos) en dos categorías: las que se establecieron en ciudades-capitales y aquellas cuya acción se concentró en ciudades del interior. Este binomio encarna dicotomías fomentadas en el corazón de la brasilidad y de la latinidad, tales como: ambiente urbano y ambiente rural; centro y periferia; modernidad y tradición (Martín-Barbero, 1998). Estos umbrales ya figuraban temáticamente en los primeros folletines narrativos producidos en las Américas (Gledhill, 1987; Martín-Barbero, 1992a), y explican en el plan narrativo, el funcionamiento de la modernidad no-contemporánea a la que se refiere Martín-Barbero (1998) para subrayar las discontinuidades y los destiempos propios del espacio latinoamericano, incluso en lo que respecta a la relación entre Estado y nación.

Un poco más de la mitad de las telenovelas brasileñas consultadas (369 títulos, o el 54,5\% del monto total) tenían como escenario las regiones metropolitanas del llamado eje RíoSão Paulo. Por lo tanto, optamos por dividir la categoría de ciudades-capitales de Brasil en tres segmentos: la ciudad de São Paulo; la ciudad de Río de Janeiro; y otras capitales del país. Esta última, sin embargo, corresponde a un volumen muy pequeño de tramas $(0,3 \%)$. Dicho dato no nos sorprende cuando miramos la historia del desarrollo de la televisión brasileña: São Paulo y Río de Janeiro son los principales mercados consumidores del país, y desde el inicio de televisión brasileña se configuraron como los lugares más propicios para la instalación de las sedes de las estaciones de alcance nacional.

${ }^{5}$ Campedelli (1985) define plot como un evento alrededor del cual los personajes "gravitan". La autora considera que las telenovelas brasileñas son multiplots - o sea, sus narrativas necesitan varios personajes y tramas, además de las principales, debido a su larga duración-. Eco (1979) llama a las ficciones que presentan esta característica como historias centrifugas. 
Además de la primacía de las dos ciudades en la ambientación espacial de las telenovelas en Brasil -que, por su larga duración y los costos implicados en la producción, difícilmente podrían ser realizadas por emisoras regionales-, este factor también sirvió para darle predominio a una mirada sudestina (del sudeste) en las tramas ambientadas en otras partes del país. En una dinámica similar a la generada en la relación centro-periferia, mientras São Paulo y Río de Janeiro, localizadas en la región Sudeste de Brasil ${ }^{6}$, se proyectaban en la ficción televisiva permeadas por ideales de modernidad (la segunda más que la primera), las narrativas ubicadas en otras regiones -especialmente en municipios del Nordeste del país, a menudo ficticios, tomados como microcosmos (Porto, 2011) de la nación- aludían frecuentemente a la idea de un "Brasil profundo" y arcaico.

\section{Entre los "espacios narrados" y los "espacios vividos" de la nación brasileña}

La agrupación de los hallazgos empíricos de la investigación por décadas nos permite reflexionar mejor sobre las articulaciones entre el ámbito cultural, el ámbito político y las instancias ideológicas -es decir, las intersecciones entre cultura y poder (Escosteguy, 2010)que son patentes y latentes en el circuito televisión y sociedad a lo largo de la historia de la telenovela en Brasil.

Gráfico 1. Tendencias de la ambientación espacial de las telenovelas brasileñas por década

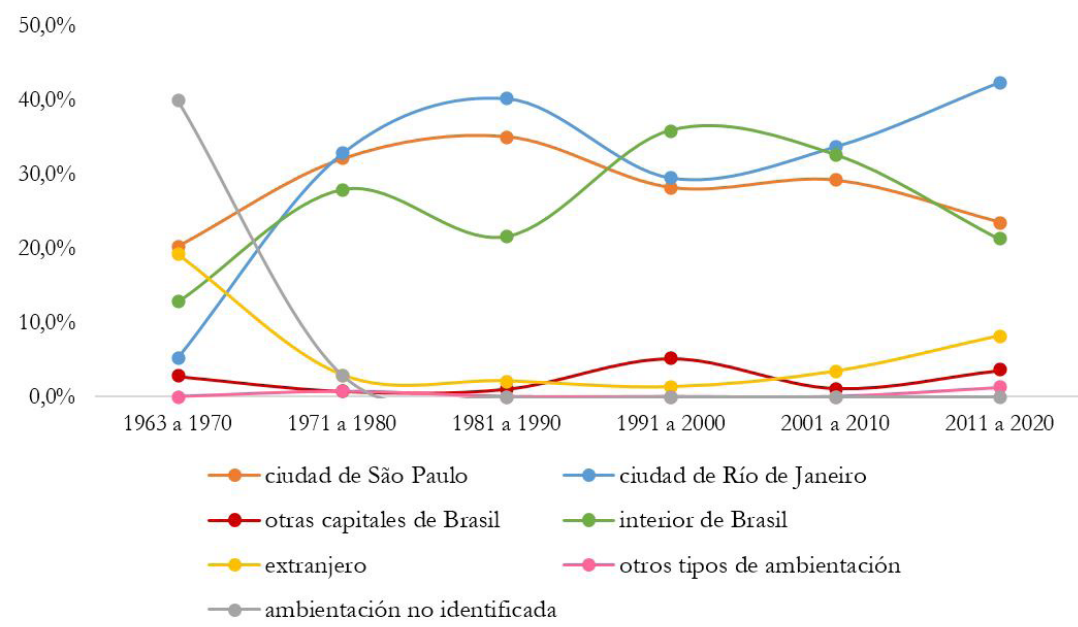

Fuente: elaborado por el autor (2022)

${ }^{6}$ Según la regionalización oficializada por el Instituto Brasileño de Geografía y Estadística (IBGE) el 23 de noviembre de 1970. 
São Paulo es la metrópoli más grande y poblada del país. Figura como escenario preponderante de las telenovelas vehiculadas en la década de 1960 debido a que Tupi y Excelsior, las dos estaciones que más produjeron ficciones televisivas en ese período, tenían sus sedes ubicadas en esta ciudad. Estos canales ya no están activos. Tupi fue el primer canal de televisión de América Latina, inaugurado en 1950 y declarado en quiebra en 1980. En 1968 emitió la telenovela Beto Rockfeller, señalada por Campedelli (1985), Hamburger (2005) y Vassallo de Lopes (2009) como un hito en la historia de la televisión; la configuración socio-geográfica de São Paulo fue un elemento esencial para la trama de la obra, más allá del carácter meramente ilustrativo verificado en las ambientaciones de narrativas anteriores. Excelsior, a su vez, fue inaugurada en 1960 y cerrada en 1970.

La São Paulo de/en las telenovelas es el centro de los negocios, de las multitudes, de la velocidad -etiquetas que se le atribuyen desde la década de 1920, momento en que se inició el boom de crecimiento y urbanización responsable por transformarla en una metrópoli moderna (Sevcenko, 1992)-. Su geografía humana está formada por familias tradicionales en decadencia y nuevos inmigrantes ricos. También es la ciudad del trabajo industrial, categoría que, no por casualidad, tiene profundas intersecciones con el imaginario migratorio enraizado en la cultura brasileña. Todos estas cuestiones fueron trabajadas tanto a través de la comedia, en obras como O Cara Suja (Tupi, 1965), Guerra dos Sexos (Guerra de los sexos ${ }^{7}$, Globo, 1983), Sassaricando (Globo, 1987), Rainha da Sucata (La reina de la chatarra, Globo, 1990), As Filhas da Mãe (Globo, 2001) y Haja Coração (Aguanta corazón, Globo, 2016), como por el drama en Antônio Maria (Tupi, 1968), A Fábrica (La fábrica, Tupi, 1971), Os Ossos do Barão (Los huesos del barón, Globo, 1973), Os Imigrantes (Los inmigrantes, Bandeirantes , 1981), A Próxima Vitima (La próxima víctima, Globo, 1995), Terra Nostra (idem, Globo, 1999) y Passione (idem, Globo, 2010).

El imaginario de la inmigración vinculado a São Paulo se retroalimenta en gran medida del proyecto modernizante idealizado por las élites de la ciudad entre fines del siglo XIX y principios del XX, en el que el blanqueamiento racial de la población es un vector fundamental. $\mathrm{Al}$ analizar documentos oficiales, periódicos, fotografías y textos literarios relacionados con São Paulo producidos en el período de la Belle Époque brasileña -cuando el municipio comienza a proyectarse como centro económico nacional-, Santos (2017) notó la ausencia de grupos étnicos además de los representados, en los estratos más bajos, por inmigrantes caucásicos (especialmente los de origen italiano). En los registros de una São Paulo que comenzaba a crecer rápidamente, pobres, negros, mestizos, caboclos, indios y caipiras aparecen en el fondo o fuera del foco central de los materiales literarios y fotográficos.

Este estigma se perpetúa en la ficción televisiva brasileña en general y no solamente en las tramas ambientadas en São Paulo. En estos casi 60 años de telenovelas diarias, la mayoría de las narrativas han asociado predominantemente la "negritud" con el arquetipo de la subalternidad, mismo cuando Brasil es un país en el que más de la mitad de la población

\footnotetext{
${ }^{7}$ Insertamos entre paréntesis el título en español de las telenovelas que circularon en países hispanohablantes.
} 
se declara negra o parda. Como describe Araújo (2019), la mayoría de estas producciones reservó a los actores afrobrasileños personajes sin o casi sin ninguna acción, restringidos al espacio de la domesticidad o a la realidad de las calles y de las favelas.

Río de Janeiro, capital federal entre 1763 y 1960, adquirió un papel protagónico en las telenovelas producidas en Brasil a partir de los 1970, momento en que Globo, inaugurada en 1965, consolidó su liderazgo de audiencia ${ }^{8}$. Con sede en la ciudad, la emisora convierte a Rio de Janeiro en el escenario principal de sus ficciones, modernizando su lenguaje teledramatúrgico como consecuencia del éxito de Beto Rockefeller. Las contradicciones de la metrópoli carioca comienzan a estructurar tramas que favorecen una propuesta realista (Ramos \& Borelli, 1989; Vassallo de Lopes, 2009; Ribeiro \& Sacramento, 2014). Sin embargo, el melodrama permanece actuando en el desarrollo de los enredos y en las direcciones morales de las narrativas, moldeando (en el doble sentido de marco externo y estructuración interna) los dilemas de la brasilidad evidentes en el circuito televisión y sociedad.

Para Ramos y Borelli (1989), la modernización de la propia sociedad brasileña exigió una reformulación de las narrativas televisivas con el objetivo de nutrir las demandas de nuevos segmentos del público. En la década de 1970, el desplazamiento de trabajadores rurales hacia los centros urbanos se intensificó en todo Brasil, especialmente en la región Sudeste. Así, títulos como Selva de Pedra (Selva de cemento, Globo, 1972), cuyo protagonista sale del interior y entra en contacto con la frívola atmósfera que envuelve a sus ricos parientes en Río de Janeiro, resumían los desafíos de muchos espectadores que se arriesgaron a migrar a la gran ciudad (Hamburger, 2005).

De esta manera, la telenovela se consolida como un espacio de narración sobre la nación (Vassallo de Lopes, 2009) en el momento en que se acentúa la urbanización y reestructuración del perfil demográfico de Brasil. En simultáneo, con el objetivo de legitimar la televisión como medio artístico, las emisoras contratan varios profesionales del sector cultural (muchos de ellos desempleados por la fuerte censura de las artes impulsada por la dictadura), especialmente venidos del teatro, que estaban dotados de una visión estética modelada por el realismo crítico. Se suma a esto la demanda indirecta del propio Estado sobre temas relacionados a la "realidad nacional". Basado en un ideal de integración del país, el régimen militar terminó endulzando las nociones de pueblo-nación que, hasta el golpe de 1964, predominaban en el pensamiento cultural de izquierda (Ramos \& Borelli, 1989; Ribeiro \& Sacramento, 2014).

El Río de Janeiro que emerge de la ficción televisiva es del "tipo exportación”, en el que prima la modernidad y la liberación de costumbres - una representación que también encuentra apoyo en motivos simbólicos e históricos, tales como la "Ciudad Maravillosa" o postal del país-. Como subraya Stocco (2009), las narrativas acentúan una yuxtaposición socio-geográfica: la Zona Sur de Río representa el lujo, el refinamiento, la sofisticación de

${ }^{8}$ La estación mantiene tal estatus hasta el día de hoy, y esto también la convirtió en la principal exportadora de telenovelas del país: desde finales de los 1970, las ficciones de Globo son significativos agentes del soft power brasileño. 
los ricos, mientras que los barrios suburbanos presentan la informalidad, sencillez, expansión y alegría de lo popular. Es por ello que el suburbio suele albergar los núcleos de humor de las telenovelas, mientras que los "dramas más serios" se desarrollan desde la Zona Sur.

Esta geografía dramática se puede ver en Pecado Capital (idem, 1975), Pai Herói (Papá héroe, 1979), Baila Comigo (Baila conmigo, 1981), Vale Tudo (Vale todo, 1988), O Dono do Mundo (El dueño del mundo, 1991), Por Amor (idem, 1997), Lacos de Família (Lazos de familia, 2000), O Clone (El clon, 2001), Celebridade (Celebridad, 2003), Senhora do Destino (Señora del destino, 2004), América (idem, 2005), Caminho das Índias (India, una historia de amor, 2009) y A Força do Querer (Querer sin limites, 2017), todas de Globo; Tudo ou Nada (1986) y Carmem (1987), de Manchete; y Prova de Amor (Prueba de amor, 2005), Amor e Intrigas (idem, 2007), Chamas da Vida (Llamas de la vida, 2008), Balacobaco (Los tramposos, 2012) y Topíssima (idem, 2019), de Record, entre otras tramas.

El Río “tipo exportación” de/en la teleficción comienza a ser deconstruido con mayor énfasis a partir de 2000. En la década anterior, la violencia en la ciudad ganó la atención de los medios, y la telenovela Guerra sem Fim (Guerra sin fin, Manchete, 1993) surgió como la primera en la que una favela asume el centro de acción. Esto se repetirá más adelante en Vidas Opostas (Vidas opuestas, Record, 2006), en un período en el que Brasil vive un auge de los llamados "favela movies" - películas que, influenciadas por el éxito mundial de Cidade de Deus (Ciudad de Dios, 2002), traen estos entornos como telón de fondo, tratando muchas veces temas de violencia explícita y narcotráfico-. Sin embargo, las telenovelas de Globo que abordan la favela, como Duas Caras (Dos caras, 2007), Salve Jorge (La guerrera, 2013), Babilônia (Mujeres ambiciosas, 2015) y A Regra do Jogo (Reglas del juego, 2015), aprovechan la capacidad niveladora y tipificadora del melodrama para atribuir a estos espacios las mismas características que se ven en los constructos de suburbio, desarrollando así una especie de "amalgama de periferia".

En la década de 1990 se observa un expresivo crecimiento de títulos ambientados en el interior del país. Probablemente, se debió al éxito de Pantanal, exhibida en 1990 por Manchete -una emisora fundada en 1983 y cerrada en 1999-. Pantanal llevó imágenes y personajes del Centro-Oeste brasileño a la televisión, ganando el primer lugar en la audiencia. La trama es, de hecho, una novedad por su dirección cinematográfica, en la que se supo explorar los paisajes bucólicos de la región. La forma en que se trabajó el binomio metrópoli/interior en la obra contribuyó a una lectura positiva del universo rural del país frente al ambiente moderno, pero "violento" e "inmoral", de la gran ciudad (Hamburger, 2005).

La representación del interior de Brasil en las telenovelas no es muy diferente de cierto imaginario relativo a los pequeños pueblos cultivado en toda Latinoamérica (véanse algunas obras de autores como Manuel Puig, Isabel Allende, Mario Vargas Llosa y, por supuesto, Gabriel García Márquez). Estas localizaciones suelen estar delineadas con pinceladas de atraso, mostrando extrema rigidez en sus jerarquías políticas, domésticas y en las demarcaciones sociales o sexuales moldeadas por las tramas (Martín-Barbero, 1992c). No es infrecuente que tales espacios presenten problemáticas como un escaso acceso a la educación, a los bienes culturales y a determinados servicios y recursos, además de la falta de oportunidades de ascenso social. Las ciudades del interior imaginadas por las telenovelas brasileñas 
son una especie de "Otro" (Said, 1978) de la modernidad, un "Otro" (el Brasil rural, de la tradición) que se construye precisamente porque la mirada de la esfera productora parte del eje Río-São Paulo.

Esto es aún más evidente en las ficciones ambientadas en la región Nordeste del país. Estas telenovelas se transfiguraron en actores significativos en un proceso que Albuquerque Júnior (2011) llama nordestinización, ampliamente visto en la literatura, la academia, la cultura y las artes brasileñas en general. Así como Said (1978) ve a Oriente como una invención de Occidente, Albuquerque Júnior sostiene que el Nordeste de Brasil es una espacialidad históricamente fundada, originada por una tradición de pensamiento, una imaginería y textos que le dieron realidad y presencia. En este transcurso, hay una cristalización de estereotipos que son subjetivados para sonar característicos del ser nordestino y de la región en su conjunto, borrando la multiplicidad de imágenes y discursos regionales.

En cuanto a la televisión, tramas como O Bem-Amado (El bien amado, 1973), Gabriela (idem, 1975), Saramandaia (1976), Roque Santeiro (idem, 1985), Tieta (idem, 1989), Pedra sobre Pedra (Te odio, mi amor, 1992), A Indomada (La indomable, 1997), Porto dos Milagres (Puerto de los Milagros, 2001), Cordel Encantado (Cuento encantado, 2011) y Velho Chico (Viejo río, 2016), de Globo; Rosa Baiana (1981), de Bandeirantes; y Mandacaru (1997), de Manchete, actuaron en la proyección y retroalimentación de este Nordeste brasileño "inventado" -una tierra de miseria, atormentada por el hambre y fundada en la tradición, dominada por coroneles y poblada por personajes folclóricas-.

A partir de estas consideraciones, tenemos las bases para lo que llamamos la "amalgama del Brasil profundo": aunque hay "Otros Brasiles", en plural, ellos convergen, desde la perspectiva de la mirada sudestina, en una sola entidad. En el centro de la idea de forjar un microcosmos de Brasil (Porto, 2011) -en los que se percibe la perversa permanencia del anacronismo (Hamburger, 2005)-, hay toda una articulación de imágenes y discursos canónicos orquestados y nivelados por el melodrama en consubstanciación con regionalismos que atraviesan la cuestión nacional en el país desde el siglo XIX (Albuquerque Júnior, 2011). Estos constructos aún contienen lo exótico o lo pintoresco.

Como ejemplo de otras ficciones que presentaron estas construcciones, podemos citar Redenção (Excelsior, 1966), Irmãos Coragem (Hermanos Coraje, Globo, 1970), Meu Pedacinho de Chão (Globo/TV Cultura, 1971), Os Inocentes (Tupi, 1974), Cabocla (idem, Globo, 1979), Paraíso (Ciudad Paraíso, Globo, 1982), Jerônimo (SBT, 1984), O Salvador da Pátria (Sassá Mutema, Globo, 1989), Fera Ferida (Fiera herida, Globo, 1993), O Rei do Gado (El rey del ganado, Globo, 1996), Dona Anja (SBT, 1996), Serras Azuis (Bandeirantes, 1998), Cidadão Brasileiro (Marcas del destino, Record, 2006), Desejo Proibido (Deseo probibido, Globo, 2007), Revelação (SBT, 2008), Ribeirão do Tempo (Río de intrigas, Record, 2011), O Outro Lado do Paraíso (El otro lado del paraíso, Globo, 2018) y O Sétimo Guardião (Globo, 2019).

En los 2010 verificamos un aumento porcentual de tramas ambientadas íntegramente en el extranjero. Este hecho se debe principalmente a las telenovelas bíblicas de Record, la emisora más antigua que opera en Brasil. Inaugurada en 1953, Record fue adquirida en 1989 
por Edir Macedo, fundador y líder de la denominación neo pentecostal Iglesia Universal del Reino de Dios. Desde 2010, la cadena se ha dedicado a la producción continua de ficciones religiosas, invirtiendo en narrativas de larga serialidad de este género a partir de 2015, con la realización de Os Dez Mandamentos (Moisés y los diez mandamientos). Como resultado, se produjeron otras cinco telenovelas bíblicas: tres ambientadas en lugares descritos en el Antiguo Testamento - A Terra Prometida (Josué y la tierra prometida, 2016), O Rico e Lázaro (El rico y Lázaro, 2017) y Jezabel (idem, 2019)-, una que contempla el tiempo de la vida de Cristo -Jesus (Jesús, 2018)-; y una contemporánea - Apocalipse (Apocalipsis, 2017), cuya acción principal se concentró en Río de Janeiro-.

Además de ampliar la penetración de Record en el mercado televisivo de América Latina, uniéndose a narrativas melodramáticas de otros países que también han tenido éxito en la región ${ }^{9}$, estas ficciones bíblicas rescatan un patrón muy explorado en la primera década de la telenovela brasileña: enredos ambientados no solo en lugares, sino en tiempos remotos. De los 53 títulos exhibidos entre 1963 y 2020 cuyas tramas se desarrollaron en el extranjero, 50 desarrollaron su acción en el pasado. Si bien no fue posible identificar con precisión el escenario temporal de las tres obras restantes de este total, este dato revela un modelo significativo.

Telenovelas llamadas folletines exóticos por Campedelli (1985), fantasías por Hamburger (2005) y sentimentales por Vassallo de Lopes (2009), transmitidas en la era "pre-Beto Rockefeller", presentaban jeques, princesas indefensas o aristócratas extranjeros en medio de trajes pomposos y ambientes palaciegos. No por casualidad, uno de los títulos más simbólicos de este período es O Sheik de Agadir (Globo, 1966), cuya trama se desarrolló entre Marruecos y Francia, mezclando árabes, alemanes nazis y ciudadanos franceses sometidos a la ocupación por las tropas de Hitler en la década de 1940. Esta telenovela es ejemplar al demostrar cómo el exotismo y la fascinación por el "Otro" -un otro imaginado- también son factores esenciales en las representaciones de países extranjeros propuestas por la televisión brasileña.

Esta imaginación del exterior en las telenovelas no se restringe, sin embargo, a la primera y última décadas cubiertas por la investigación. El clon, América, India, una bistoria de amor y La guerrera, ficciones escritas por Gloria Pérez, tuvieron su acción dividida entre Río de Janeiro y un lugar extranjero ${ }^{10}$-regiones de Marruecos, Estados Unidos, India y Turquía, respectivamente-. Calificadas por Vassallo de Lopes (2009) como naturalistas, tales tramas no rehuyeron utilizar el modo ético y emocional de conceptualización y dramatización del melodrama al retratar estas culturas. Creencias, valores, aspiraciones y enseñanzas religiosas de los pueblos representados fueron, muchas veces, presentados como un contrapunto entre "nosotros" (la nación brasileña) y "ellos" (los "Otros").

\footnotetext{
${ }^{9}$ Los recientes informes del Observatorio Iberoamericano de la Ficción Televisiva (OBITEL) subrayan que narrativas melodramáticas turcas, surcoreanas e indias han conquistado a las audiencias latinoamericanas en los últimos años.

${ }^{10}$ Como ya explicamos en la sección 3 de este trabajo, consideramos que dichas tramas fueron ambientadas en Río de Janeiro con el propósito de tabular y comparar los datos empíricos de la investigación.
} 
Finalmente, de los 598 títulos en que pudimos determinar la ubicación espacial de los enredos, dos no se ajustan en coordenadas geográficas de la realidad (clasificados en la tabla 1 como "otros tipos de ambientación"): Cinderela 77 (Tupi, 1977) y Meu Pedacinho de Chão (Globo, 2014). La primera, una actualización de la historia de Cenicienta, tiene su enredo ambientado en el Reino de la Calabaza. Meu Pedacinho de Chão, a su vez, es un remake de la telenovela homónima de 1971. En la primera versión, la ficticia Santa Fe -el escenario de los principales hechos de la trama- era un típico pueblo del interior de Brasil. La narrativa presentó temas relacionados con la vida y los problemas de los campesinos, muchos de los cuales permanecieron en la versión de 2014, aunque la dirección de la obra le dio una atmósfera mágica, localizando la acción en un "mundo de sueños".

\section{Consideraciones finales}

En este trabajo, buscamos visualizar los sentidos de la identidad nacional articulados por las telenovelas brasileñas en los últimos 60 años a través de factores vinculados a la noción de espacio. Desde una perspectiva culturalista (Haesbaert, 2011), observamos que estas ficciones se apropiaron mayoritariamente de un imaginario geo-social engendrado en su país de origen entre finales del siglo XIX y principios del XX, precisamente el período de consolidación de los medios de comunicación de masa -cuando la imaginación moderna de Brasil estaba tomando forma-. Por lo tanto, no es casual que la oposición entre localidades metropolitanas y pequeños pueblos del interior, como ya enfatiza Hamburger (2005), constituya uno de los principales ejes narrativos de estas producciones: tal dicotomía remite a un ideal históricamente proyectado sobre el binomio modernidad/tradición.

Construidas a partir de estas condiciones, las ambientaciones espaciales descriptas en las páginas anteriores fueron molduradas a partir de las tecnicidades disponibles en el contexto de producción de las obras, en una ecuación que involucró desde el funcionamiento de las instituciones hasta las dinámicas de las sensorialidades observadas en cada momento. A través de la intersección entre el espacio-tiempo de las narrativas y el espacio-tiempo de los procesos sociales, el melodrama orquestaba significados que a veces transgredían y a veces estampaban el orden actual, modelando una galería de historias y tipos nacionales pertinentes a las localidades retratadas. Directa o indirectamente, temas propios del marco melodramático como el amor romántico, las pasiones prohibidas, el deseo de venganza, la expectativa de recompensa después del sufrimiento, la búsqueda de la redención, etc., comenzaron a incorporar particularidades y disputas culturales, políticas e históricas de dichos espacios y, en general, de la sociedad brasileña en su conjunto.

Esta mirada al campo de fuerzas retroalimentado por la telenovela brasileña a lo largo de su historia también nos permitió identificar algunas "entrelíneas" de la ficción televisiva e incluso lo que no fue tematizado por ella, ya sea por contingentes políticos, ideológicos o de mercado, o por el impasse de transformar en narrativas fracturas que aún no han sido asimiladas por la memoria histórica nacional. Por lo tanto, el mestizaje (Martín-Barbero, 1998) entre el ethos melodramático y la brasilidad en las narrativas no dejó de consubstanciarse (con) y operar silenciamientos y ausencias -esos "Brasiles" que, parafraseando a Araújo (2019), fueron negados por el propio Brasil-. 
Así, al forjar constructos espaciales mezclados con estéticas y estigmas de todo un repertorio enraizado en la cultura y la imaginación popular-masiva de Brasil, las telenovelas son capaces de traducir las contradicciones del país en todos los aspectos: desde los meandros conscientes e inconscientes de las lógicas de producción a los de las competencias de recepción. Esto se debe principalmente a la matriz cultural de estas narrativas. Como se verificó en estudios clásicos que propusieron analizar longitudinalmente la actuación de este género/modo en otros productos mediáticos, el melodrama siempre ha demostrado una fácil adhesión a los paisajes de la modernidad. Una modernidad que, en el contexto brasileño, a menudo encontró mayor concreción y solidez en la ficción televisiva que en la realidad.

Incluso frente a la complejidad del panorama mediático contemporáneo, la telenovela sigue ocupando la centralidad de tal escenario en Brasil, estableciéndose como un importante espacio de debates para la promoción de las diferencias (Vassallo de Lopes, 2009). Sin embargo, algunos sectores de la sociedad han protestado fuertemente contra los estereotipos y patrones de exclusión aún perpetrados por estas narrativas, en un movimiento que resalta la dialéctica entre identidad y diversidad cultural característica de la problemática de la nacionalidad. Esto ocurre en un momento en el que las producciones televisivas se convierten en objeto de consumo mundial, dando lugar a modelos que, de alguna manera, cuestionan el lugar de los contenidos audiovisuales como reflejo de lo nacional. Veremos, entonces, qué mestizajes entre "antiguas" y "nuevas" imaginaciones geográficas, sensorialidades y tecnologías el melodrama orquestará en los próximos años en el corazón de la telenovela brasileña.

\section{Bibliografía}

Albuquerque Júnior, D. M. (2011). A invenção do Nordeste e outras artes. São Paulo: Cortez.

Anderson, B. (1983). Imagined Communities. Reflections on the Origin and Spread of Nationalism. Londres: Verso.

Araújo, J. Z. (2019). A negação do Brasil. O negro na telenovela brasileira. São Paulo: Senac.

Bhabha, H. K. (1990). Nation and Narration. Londres: Routledge.

Bonin, J. A. y Morigi, V. J. (2019). Ciudadanía en las interrelaciones entre comunicación, medios y culturas. En N. Jacks, D. Schmitz y L. Wottrich (Eds.), Un nuevo mapa para investigar la mutación cultural. Diálogo con la propuesta de Jesús Martín-Barbero (pp. 215-239). Quito: Ciespal.

Bonnemaison, J. y Cambrèzy, L. (1996). Le lien territorial : entre frontières et identités. Géographie et cultures 20, Francia, pp. 7-18.

Brignol, L. D., Cogo, D. y Lago Martínez, S. (2019). Redes: dimensión epistemológica y mediación constitutiva de las mutaciones comunicacionales y culturales de nuestro tiempo. En N. Jacks, D. Schmitz y L. Wottrich (Eds.), Un nuevo mapa para investigar la mutación cultural. Diálogo con la propuesta de Jesús Martín-Barbero (pp. 187-214). Quito: Ciespal. 
MHJournal Vol. 13 (1) | Año 2022 - Artículo no 4 (197) - Páginas 81 a 100 - mhjournal.org

Campedelli, S. Y. (1985). A telenovela. São Paulo: Ática.

Eco, U. (1979). The Role of the Reader. Explorations in the Semiotics of Texts. Bloomington: Indiana University Press.

Escobar, A. (2000). El lugar de la naturaleza y la naturaleza del lugar: ¿globalización o postdesarrollo? En E. Lander (Ed.), La colonialidad del saber: eurocentrismo y ciencias sociales. Perspectivas latino-americanas (pp. 108-138). Buenos Aires: Clacso.

Escosteguy, A. C. (2010). Cartografias dos Estudos Culturais. Uma versão latino-americana. Belo Horizonte: Autêntica.

Fuentes-Navarro, R. (2021). La investigación postdisciplinaria como alternativa en Comunicación. Revista de la Asociación Española de Investigación de la Comunicación 8(15), España, pp. $2-23$.

García Canclini, N. (1996). Ciudades y ciudadanos imaginados por los medios. Perfiles Latinoamericanos 5(9), México, pp. 9-24.

Geertz, C. (1983). La interpretación de las culturas. Barcelona: Gedisa.

Gledhill, C. (1987). The Melodramatic Field: An Investigation. En C. Gledhill (Ed.), Home Is Where the Heart Is. Studies in Melodrama and the Woman's Film (pp. 5-39). Londres: British Film Institute.

— (2000). Rethinking Genre. En C. Gledhill y L. Williams (Eds.), Reinventing Film Studies (pp. 221-243). Londres: Arnold.

Gomes, I. M. M. (2011). Gênero televisivo como categoria cultural: um lugar no centro do mapa das mediações de Jesús Martín-Barbero. Revista Famecos 18(1), Brasil, pp. 111-130.

—, Santos, T. E. F., Araújo, C. S. G. y Mota Junior, E. A. (2018). Temporalidades múltiplas: análise cultural dos videoclipes e da performance de Figueroas a partir dos mapas das mediações e das mutações culturais. Contracampo 36(3), Brasil, pp. 134-153.

Haesbaert, R. (2011). El mito de la desterritorialización. Del "fin de los territorios" a la multiterritorialidad. Ciudad de México: Siglo XXI.

Hamburger, E. I. (2005). O Brasil antenado. A sociedade da novela. Río de Janeiro: Zahar.

Kornis, M. A. (2011). Ficção televisiva e identidade nacional: o caso da Rede Globo. En M. H. R. Capelato, E. V. Morettin, M. Napolitano y E. T. Saliba (Eds.), História e cinema. Dimensões históricas do audiovisual (pp. 97-114). São Paulo: Alameda.

Martín-Barbero, J. (1992a). El proyecto: producción, composición y usos del melodrama 
televisivo. En J. Martín-Barbero y S. Muñoz (Coords.), Televisión y melodrama. Géneros y lecturas de la telenovela en Colombia (pp. 19-37). Bogotá: Tercer Mundo Editores.

-. (1992b). Claves para re-conocer el melodrama. En J. Martín-Barbero y S. Muñoz (Coords.), Televisión y melodrama. Géneros y lecturas de la telenovela en Colombia (pp. 39-60). Bogotá: Tercer Mundo Editores.

- (1992c). Transformaciones del género: de la telenovela em Colombia a la telenovela colombiana. En J. Martín-Barbero y S. Muñoz (Coords.), Televisión y melodrama. Géneros y lecturas de la telenovela en Colombia (pp. 61-106). Bogotá: Tercer Mundo Editores.

-. (1998). De los medios a las mediaciones. Comunicación, cultura y hegemonía. Bogotá: Convenio Andrés Bello.

Morin, E. (2007). La cabeza bien puesta. Repensar la reforma, reformar el pensamiento. Buenos Aires: Nueva Visión.

Motter, M. L. (2001). A telenovela: documento histórico e lugar de memória. Revista USP (48), Brasil, pp. 74-87.

Néia, L. M. (2018). Del teatro francés del siglo XVIII a la ficción televisiva transnacional del siglo XXI: el melodrama como paradigma transgénero, transcultural y transhistórico. En Memorias del Congreso ALAIC 2018: GI 2. Ficción televisiva y narrativa transmedia (pp. 130-135). San Pedro: Asociación Latinoamericana de Investigadores de la Comunicación. Recuperado de http://alaic2018.ucr.ac.cr/sites/default/files/2019-02/GI\%202\%20-\%20 $\underline{\text { ALAIC } \% 202018 \text { 0.pdf }}$

Porto, M. P. (2011). Telenovelas and Representations of National Identity in Brazil. Media, Culture \& Society 33(1), Reino Unido, pp. 53-69.

Ramos, J. M. O. \& Borelli, S. H. S. (1989). A telenovela diária. En R. Ortiz, S. H. S. Borelli y J. M. O. Ramos, Telenovela. História e produção (pp. 55-108). São Paulo: Brasiliense.

Rancière, J. (2004). The Politics of Aesthetics. The Distribution of the Sensible. Londres: Continuum.

Ribeiro, A. P. G. y Sacramento, I. P. (2014). A moderna telenovela brasileira. En A. P. G. Ribeiro, I. P. Sacramento y M. A. Roxo (Eds.), Televisão, história e gêneros (pp. 156-191). Río de Janeiro: Multifoco.

Rincón, O. (2019). Epílogo: mi invención sobre el mapa para comprender el sensorium de la contemporaneidad. En N. Jacks, D. Schmitz y L. Wottrich (Eds.), Un nuevo mapa para investigar la mutación cultural. Diálogo con la propuesta de Jesús Martín-Barbero (pp. 263-274). Quito: Ciespal. 
MHJournal Vol. 13 (1) | Año 2022 - Artículo no 4 (197) - Páginas 81 a 100 - mhjournal.org

Said, E. W. (1978). Orientalism. Nueva York: Pantheon Books.

Saliba, E. T. (2002). Raǐes do riso. A representação bumorística brasileira: da Belle Époque aos primeiros tempos do rádio. São Paulo: Companhia das Letras.

Santos, C. J. F. (2017). Nem tudo era italiano. São Paulo e pobreza (1890-1915). São Paulo: Annablume.

Santos, M. (1990). Por una geografía nueva. Madrid: Espasa-Calpe.

Sevcenko, N. (1992). Orfeu extático na metrópole. São Paulo, sociedade e cultura nos frementes anos 1920. São Paulo: Companhia das Letras.

Sifuentes, L. y Zanini, M. C. C. (2019). Las identidades en el contexto de las mutaciones tecnológicas. En N. Jacks, D. Schmitz y L. Wottrich (Eds.), Un nuevo mapa para investigar la mutación cultural. Diálogo con la propuesta de Jesús Martin-Barbero (pp. 241-261). Quito: Ciespal.

Sodré, M. (2014). A ciência do comum. Notas para o método comunicacional. Petrópolis: Vozes.

Stocco, D. (2009). Paraíso Tropical. Interpretação de um país através de uma cidade e uma novela. (Tesis de maestría). Universidad Federal de Río de Janeiro, Río de Janeiro.

Vassallo de Lopes, M. I. (2004). Pesquisa de comunicação: questões epistemológicas, teóricas e metodológicas. Revista Brasileira de Ciências da Comunicaşão 27(1), Brasil, pp. 13-39.

— (2009). Telenovela como recurso comunicativo. MATRIZes 3(1), Brasil, pp. 21-47.

- (2018). A teoria barberiana da comunicação. MATRIZes 12(1), Brasil, pp. 39-63. 
MHJournal Vol. 13 (1) | Año 2022 - Artículo n 4 (197) - Páginas 81 a 100 - mhjournal.org

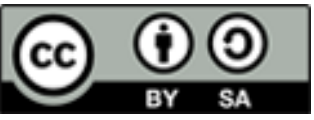

Licencia Creative Commons

Miguel Hernández Communication Journal

mhjournal.org

\section{Cómo citar este texto:}

Lucas Martins Néia (2022): Estéticas y estigmas de/en la geografía imaginada de la telenovela brasileña, en Miguel Hernández Communication Journal, Vol. 13 (1), pp. 81 a 100. Universidad Miguel Hernández, UMH (Elche-Alicante). DOI: 10.21134/mhjournal. v13i.1465 